\title{
Representaciones de la ciudad análoga. Una revisión metodológica para los estudios culturales urbanos
}

\section{CAROLINA LAZTRA}

carolina.laztra@gmail.com - Centro Nacional Patagónico, Universidad Nacional de la Patagonia (UNP), Argentina

Fecha de recepción: 20 de abril de 2017

Fecha de aceptación: 31 de mayo de 2017

\section{RESUMEN}

Este artículo analiza la figura de la ciudade análoga comoherramientaparapensarla ciudad y sus múltiples representaciones. Se plantean dositinerariosen el presente trabajo. Uno se vincula al pensamiento intelectual urbano que ha desarrollado diversos caminos de análisis del espacio de la ciudad. Y el otro enfoca su interés en el campo narrativo de Georges Perec e Italo Calvino, donde se expresa el rol de la memoria y la imaginación como detonadores del conocimiento sobre la ciudad. La interpretación del tiempo múltiple, entendiéndolo como heterogéneo y fragmentado, constituye una constelación de sentidos que configura ambas obras literarias, a la luz del pensamiento sobre la cultura de la ciudad.

PALABRAS CLAVES: espacio urbano, representaciones, memoria, ciudad análoga

\section{ABSTRACT}

This article examines the figure of the analogous cities like tool to consider the city and its representations. This work presents two itineraries. One gets connected to the intellectual urban thought that has unrolled various roads of analysis of the space of the city. And the other one focuses his interest at Georges Perec's narrative field and Italo Calvino, where the role of memory and the imagination like detonators of the knowledge on the city are expressed. The interpretation of the multiple time, heterogeneous and fragmented, constitute a constellation of senses that configures both literary productions, in the light of thinking about the culture of the city.

KEY WORDS: urban space, memory, representations, analogous city 


\section{BREVE REVISIÓN DEL PENSAMIENTO SOBRE EL ESPACIO DE LA CIUDAD}

La interrogación por la ciudad y sus múltiples formas ha sido objetivo de una diversidad de disciplinas: geografía, historia, sociología, filosofía, antropología, economía, entre otras. La necesidad de un punto de partida donde el espacio no es amorfo, sino parte constitutiva de los procesos sociales, ha ido demarcando un largo recorrido en el estudio de la ciudad.

Desde una relectura del marxismo clásico, Henri Lefebvre fue una figura central del pensamiento sobre la ciudad, al repensar los procesos espaciales. La transformación de las ciudades bajo la lógica acumulativa del capitalismo, de alguna manera reformuló a las mismas como objeto de estudio específico, constituyéndolas como un subsistema privilegiado para el análisis espacial (Pascual, 2014). Incorporar los procesos sociales en el enfoque disciplinar fue la propuesta de David Harvey (1985), para quien es central la imaginación geográfica o conciencia espacial, dado que permite comprender el papel del espacio en la trayectoria personal y en la de las otras personas. Se trata de establecer "las relaciones entre forma espacial, significado simbólico y comportamiento espacial” (1985, p. 26).

En esta línea, hacia la década de 1990, la geografía poscolonial ahondó en el concepto de imaginación geográfica, al vincular este campo con la dominación colonial; ya sea a través de sus intervenciones materiales como sus conceptualizaciones y discursos (Zusman, 2012). Edward Said (1978) fue una fuente de inspiración para estos estudios. Su obra Orientalismo explica que la relación poder-conocimiento sobre Oriente se expresa en estas geografías imaginarias ${ }^{1}$, reforzando así la noción de que la expansión imperialista fue producto no sólo de estrategias militares y políticas, sino también de la cultura en la construcción de hegemonía. Influenciado por esta corriente, Derek Gregory ha analizado los espacios coloniales pero proponiéndolos más inestables y ambivalentes, a fin de comprender las estrategias epistemológicas de la modernidad que ordenan y jerarquizan estos imaginarios geográficos (Zusman, 2012).

Vinculadas al concepto imaginarios, pero desde un enfoque interdisciplinar, surgen investigaciones que ponen el foco en el carácter simbólico de la ciudad y cómo las diversas representaciones organizan los sentidos sobre el espacio de lo urbano (Pascual, 2014). Armando Silva y Néstor García Canclini teorizaron sobre esta perspectiva, enfocandolas dimensiones subjetivas. Según Canclini (2007), los imaginarios son centrales para establecer relaciones de localización de los sujetos:

1 Zusman explica que "los imaginarios geográficos de Said promovieron el desarrollo en la geografía histórica un conjunto de líneas de trabajo que se interesaron por explorar las representaciones, fantasías y sueños sobre los espacios de 'los otros' vehiculizados a través de los relatos de viaje, de las fotografías, las pinturas ylas cartografías” (2012, p. 57). 
¿Desde dónde nos hablan? ¿Quién es el que nos habla? ¿Qué posición ocupa en la ciudad? ¿Cómo se identifica? ¿Cómo conviene interactuar en relación con él? ¿Qué rol vamos a desempeñar de los muchos que actuamos dentro de una ciudad heterogénea? (2007, p. 92).

Los estudios latinoamericanos sobre las villas miseria se nutren de esta perspectiva interdisciplinar al analizar las imágenes de universos simbólicos de separación o periferia (Pascual, 2013; Liernur, 2009; Snitcofsky, 2015). Estos trabajos ahondan en la relación literatura y ciudad, al reflexionar sobre los modos de construcción de imágenes de la periferia y espacios de relegación en la Argentina del siglo XX.

Retomando el concepto de espacio como producto social (Harvey, 1998), Segura (2015) analiza la experiencia urbana y las relaciones espacio y sociedad sin reducir ni disolver ningún término. Su interés es captar las complejas relaciones entre espacio y prácticas sociales, así como las diversas formas en que las imágenes y representaciones de una ciudad se estabilizan.

Segura revela dos metáforas como punto de partida para pensar lo urbano. Por un lado, la ciudad como mosaico, heredada de la Escuela de Chicago, que defineal espacio urbano como una colección de mundos relativamente autónomos, por pertenencia étnica-racial o residencia, donde el foco son las "regiones morales", una perspectiva un tanto estática y esquemática dela ciudad. Por otro lado, la metáfora de la ciudad como flujo, con tradición en la literatura moderna y la crítica cultural de entreguerras, que remite al espacio urbano como ámbito cambiante y dinámico, reintroduciendo las interacciones sociales entre actores diferentes y desiguales, los desplazamientos y los recorridos. Evitando perder de vista o minimizar las posiciones que ocupan los actores sociales en la vida urbana, Segura (2015) explica que su objetivo es analizar posiciones y movilidades, indagando el entrelazamiento de los límites y las fronteras con las relaciones y los intercambios. Tal es el caso del capítulo I de Vivir afuera (2009), donde el autor indaga en un conjunto variado de materiales sobre la ciudad de La Plata, Capital de la Provincia de Buenos Aires: legislaciones, publicidad municipal, intervenciones y proyectos urbanos, dibujos de la ciudad y mapas elaborados por sus habitantes a fin de detectar la multiplicidad de discursos, imágenes, representaciones y relatos allí elaborados.

En este repaso genealógico por algunos de los estudios urbano-culturales más relevantes, los enfoques del historiador Adrián Gorelik ponen en escena la articulación entre cultura urbana e historia cultural como el universo de representaciones que no sólo tiene como tema la ciudad, sino que la produce. La problematización que plantea el autor es la búsqueda de las huellas entre las formas materiales y las formas culturales, es decir, el modo en que la ciudad y sus representaciones se producen mutuamente. "La grilla y el parque" de Gorelik (1998), aborda el proceso de formación del espacio público en la ciudad de Buenos Aires, construyendo a la grilla y al parque precisamente como 
unidades de análisis (Pascual, 2014). Esta investigación doctoral derivó en un interesante aporte sobre la relación entre forma y política, mediante la indagación histórica de las formas, objetos, procesos materiales, discusiones, ideas y representaciones sobre la ciudad.

\section{CIUDADES ANÁLOGAS, ¿PARA QUÉ? POSIBLES INSTRUMENTOS PARA (DES)ARMAR LOS ESTUDIOS URBANOS}

El concepto de ciudad análoga fue propuesto por el arquitecto italiano Aldo Rossi (1966), en su obra Arquitectura de la ciudad, y constituye un objeto de análisis para Gorelik (1999), quien rescata dos tradiciones del pensamiento teórico sobre las ciudades vinculadas al origen del concepto. Por un lado, una tradición culturalista; en cuyo ámbito se encuentra parte del pensamiento urbano anglosajón (especialmente Lewis Mumford) y la geografía humana francesa, que retoman el motivo del "alma de la ciudad" y conectan así las formas materiales con los problemas de la memoria colectiva. No obstante, esta tradición no ofrece instrumentos de análisis que permitan analizar el contacto entre formas materiales y formas culturales, y encierra el pensamiento al ámbito de la praxis urbanística. Por otro lado, una vertiente mucho más activa en la cultura contemporánea, proveniente del romanticismo alemán, que concibe la teoría aferrada siempre a formas, a fenómenos sensibles. De acuerdo con Gorelik, aquí los instrumentos analíticos se basan en una inteligencia poética que limita la interpretación, pues eliminan todos los aspectos no discursivos de la producción de la ciudad. Inscriptos en estas teorías se hallan Benjamin, Kracauer, Giedion, entre otros.

Rossi propuso la figura de la ciudad análoga, vinculando algunas de las tradiciones antes mencionadas de modo superador, dado que la yuxtaposición de arquitecturas que presenta esta figura, no sólo permite entender la extensa duración en que se resuelve la historia material de la ciudad, sino también el modo en que se superponen sus representaciones como productos culturales y figuraciones de la ciudad y ya no como meras arquitecturas (Gorelik, 1999). Lo que incorpora la figura de la ciudad análoga es la necesidad de incorporar todos los diferentes planos de sentido en la comprensión de la ciudad y en las propuestas urbanas, es decir, poner en juego de modo simultáneo la ciudad real, la ciudad ideal, la ciudad idealizada y la ciudad ideologizada.

De acuerdo con Segura (2009), esta figura propuesta por Rossi es un modo alternativo de acercamiento a la ciudad, más cercano a la imaginación, la intuición y los intereses personales, que al pensamiento racional. El concepto de ciudad análoga reivindicaba el proceso de diseño de la ciudad mediante el uso de la memoria colectiva de los sujetos con una misma base cultural. En el capítulo "La persistencia de la forma”, Segura (2015) analiza las ciudades análogas que conforman La Plata, y logra identificar ciertas 
"persistencias representacionales" como sedimentaciones de procesos histórico-urbanos. Cómo fue y es la ciudad es el interrogante que moviliza la investigación de Segura, intentando dilucidar las tensiones producidas entre ciudad ideal y ciudad real

En tanto que, en Miradas sobre Buenos Aires, Gorelik (2013) retoma el concepto para analizar los poemas de Daniel García Helder y los grabados de Félix Rodríguez, para interpretar el vínculo entre arte y ciudad. Dichos grabados y poemas permiten poner en secuencia, cada una por separado, momentos congelados en los que se superponen las capas de tiempo, según el historiador argentino.

\begin{abstract}
Son representaciones frágiles, que ponen en cuestión el imaginario nostálgico: critican el doble aplanamiento de la complejidad del tiempo que produce la nostalgia, que lejos de enfrentarnos a la angustia muda del futuro pasado, se consuela figurando la restauración de un pasado mitificado. Son antimonumentales, porque su condensación temporal rompe el tiempo continuo del que buscan hablar los monumentos en la ciudad cuando se convierten en íconos de la ciudad análoga naturalizada (2013, p. 153).
\end{abstract}

La figura de la ciudad análoga pone en evidencia la reproducción de valores naturalizados e inmutables, del sentido común, al develar la ficción representativa con que se experimenta la ciudad. De esta manera produce un instrumento de conocimiento para intervenir críticamente en sus figuraciones; permite desplegar las simbolizaciones culturales que produce la ciudad y que la producen, reconstruyendo su proceso de formación y su función histórica y cultural (Gorelik, 1999). En clave de lectura foucaultiana, la figura de las ciudades análogas puede entenderse como una "caja de herramientas" para pensar una situación históricamente situada, pues no se trata de construir un sistema teórico cerrado y total, sino un instrumento que permita comprender "la especificidad de los mecanismos de poder, reparar en los enlaces, las extensiones, edificar progresivamente un saber estratégico" (Foucault, 2000, p. 85). Esta idea, de acuerdo a María Graciela Rodríguez, nos traslada desde la veracidad de las representaciones hacia las cuestiones del poder y la ideología implicadas en las producciones culturales. "No será relevante entonces dar cuenta de los grados de coherencia entre lo simbólico y lo "real", sino preguntarse: ¿qué se representa?, ¿quién lo representa? y ¿cómo se representa al otro?" (Rodríguez, 2011).

\title{
LOS TERRITORIOS DISCURSIVOS DE PEREC Y CALVINO
}

La crítica a la naturalización de los espacios de la ciudad es uno de los aportes centrales de la figura de las ciudades análogas. Y en ese camino crítico, el trabajo literario de un autor como Georges Perec, fiel al estilo de un cronista 
urbano $^{2}$, aporta un conjunto de materiales de central interés en este trabajo. El campo narrativo construido por Perec se construye a partir de una mirada de lo cotidiano que parte de interrogaciones de índole sociohistóricas:

\begin{abstract}
Reconocer que los suburbios tienen una fuerte tendencia a no seguir siendo suburbios. Notar que la ciudad no ha sido siempre lo que era. Recordar, por ejemplo, que Auteuil estuvo mucho tiempo en el campo. Recordar también que el Arco de Triunfo fue edificado en el campo (...). Recordar que todo lo que se llama "faubourg" se encontraba fuera de la ciudad (...). Recordar que si se decía Saint-Germain-des-Prés, es porque allí había prados. Recordar que un "boulevard" es en su origen un paseo arbolado que rodea la ciudad y que ocupa por lo común el espacio donde estaban las antiguas murallas. Recordar, al respecto, que estaba fortificado. (Perec, 2001, pp. 97 y 98)
\end{abstract}

Estas tareas de la memoria parten de la noción de interrogación crítica de la realidad que Perec desplegó en su ensayo “iAproximación a qué?” (1991). Interrogar aquello de lo que hemos olvidado su origen y encontrar sorpresa frente a las cosas son elementos en común en sus obras, con claros matices antropológicos y biográficos tales como "La vida, instrucciones de uso", "Las cosas" o "W o recuerdo de infancia". Allí Perec asume la tarea de nombrar, acumular, enumerar, inventariar y describir larga y detalladamente su paso por el mundo, lo que el mundo contiene así como devolvernos lo que ya no percibimos del mundo. Según Becker (2015), el autor francés describe el lugar común y lo cotidiano sin un hilo conductor que permita la generalización de una idea compartida en sus relatos. Becker destaca su impronta "sociológica" al explicar la forma en que utiliza los dispositivos literarios para hablar de cuestiones de interés para las ciencias sociales, pues Perec relata de manera profunda y detallada la vida cotidiana mediante lo que Becker denomina fotoetnografías:

Pero la estrategia empleada por Perec coincide de manera llamativa con lo que algunos científicos buscan: la descripción de aquello que un grupo de personas que interactúan y se comunican en determinadas circunstancias históricas produjeron como conocimiento, entendimiento y práctica común; eso que suele denominarse "cultura". Más aún, avanza en el trabajo de producir una representación de aquello a lo que suele hacerse referencia con el término experiencia vivida (...), este debe hacer referencia al menos a este tipo de "lo que cualquiera sabe y siente" en una determinada circunstancia histórica y social. Perec llama la atención sobre aquello que podría parecer carente de interés, poco notorio, no merecedor (con total certeza) de que se elaboren teorías al respecto (ibíd., 2015, p. 300).

De un modo "extrañado" y en clave interrogativa, Perec despliega una serie de detalles sobre París en "Tentativas de agotar un paisaje parisino" (1992). El

2 Jorge Fondebrider (1992), traductor de la obra de Perec “Tentativa de agotar un paisaje parisino", definió al autor como un cronista en la tarea de explorar, describir y nombrar el espacio y lo que lo puebla, pero no sobre realidades ajenas, sino sobre aquella tangible, observable, recordable. 
autor registra "lo que pasa cuando no pasa nada" a lo largo de dos días, ensayando un relato sobre la percepción y el modo de aprehender el espacio, el barrio, la ciudad: lo que no se anota, lo que no se nota, lo que no tiene "importancia". El modo de acercamiento, cuasi fenomenológico, constituye para Perec una forma de conocimiento:

Una ciudad: piedra, cemento, asfalto. Desconocidos, monumentos, instituciones.

Megalópolis. Ciudades tentaculares. Arterias. Muchedumbres.

¿Hormigueros?

¿Qué es el corazón de una ciudad? ¿El alma de una ciudad? ¿Por qué se dice que una ciudad es bonita o fea? ¿Qué tiene de bonito y de feo una ciudad? ¿Cómo se conoce una ciudad? ¿Cómo conoce uno su ciudad?

Método: habría que renunciar a hablar de la ciudad, a hablar sobre la ciudad, o bien obligarse a hablar de ella del modo más simple del mundo, hablar de ella de forma evidente, familiar. Abandonar toda idea preconcebida. Dejar de pensar en términos muy elaborados, olvidar que han dicho los urbanistas y los sociólogos. Hay algo espantoso en la idea misma de la ciudad; se tiene la impresión de que sólo podremos aferrarnos a imágenes trágicas o desesperadas (...)

Nunca nos podremos explicar o justificar la ciudad. La ciudad está ahí. Es nuestro espacio y no tenemos otro. Hemos nacido en ciudades. Hemos crecido en ciudades. Respiramos ciudades. Cuando tomamos el tren es para ir de una ciudad a otra. No hay nada inhumano en una ciudad, como no sea nuestra propia humanidad (Perec, 1992, pp. 99 y 100).

Podríamos decir que la obra de Perec ensaya una forma de construcción de ciudades análogas en ejercicios de estratigrafía cultural (Gorelik, 1999), donde el escritor es arqueólogo de su propio presente. Ítalo Calvino, admirador de la obra de Perec, (des)arma un estilo descriptivo en estrecha relación con la memoria en Las ciudades invisibles, obra publicada en 1973, en la que un Marco Polo ficticio le relata sus viajes al emperador de los tártaros. Estos breves relatos organizados en categorías temáticas (las ciudades y el deseo, las ciudades y los intercambios, las ciudades y los signos, etc.) articulan un concepto de memoria sobre la idea atemporal de la ciudad moderna. Becker (2015) también destaca el aporte literario de la obra de Calvino a la teoría social, y compara su escritura con las etnografías que Clifford Geertz denominó "descripción densa”:

Esto plantea un claro contraste con el deseo de los urbanistas de contar con conceptos definidos con claridad que les permitan atribuir una ciudad a tal o cual categoría, afirmar que tal o cual rasgo es dominante o característico en ella, para producir un análisis definitivo. Los conceptos científicos, carentes de ambigüedad, producen resultados carentes de ambigüedad. La descripción literaria renuncia en parte a la claridad y a la unidimensionalidad para obtener, en cambio, la posibilidad de plantear múltiples análisis de las múltiples posibilidades contenidas en una misma historia (Becker, 2015, p. 318). 
Heredero de la Escuela de Chicago y el interaccionismo simbólico, Becker destaca el carácter ambiguo de las narrativas literarias en contraposición con los criterios de cientificidad. No obstante, sea como herramienta de registro o como insumo para el análisis, la literatura forja y se alimenta de significantes que representan las formas territoriales (Pascual, 2013). En tal sentido, y con intención de promover las investigaciones cualitativas en el campo de lo urbano, Richard Morse abogó por la articulación de la visión de ensayistas y novelistas con la imaginación historiográfica y sociológica (Roldán \& Pascual, 2012). El propio Walter Benjamin desarrolló su aparato crítico sobre "los pasajes de París" a partir de novelas, poesía, textos de la época que podemos llamar de "crónicas sociales", reportes oficiales, extractos de diarios, entre otros. "Benjamin construyó permanentemente su obra por medio de las lecturas más dispersas, resultando sumamente creativo en la selección” (Hiernaux, 1999, pp. 283 y 284$)$.

La narrativa que desarrolla Calvino apela a un desciframiento del espacio de las ciudades mediante un trabajo descriptivo y analítico que ahonda en las memorias, los deseos, los signos de un lenguaje y los lugares de intercambio:

\begin{abstract}
Una descripción de Zaira tal como es hoy debería contener todo el pasado de Zaira. Pero la ciudad no cuenta su pasado, lo contiene como las líneas de una mano, escrito en las esquinas de las calles, en las rejas de las ventanas, en los pasamanos de las escaleras, en las antenas de los pararrayos, en las astas de las banderas, cada segmento surcado a su vez por arañazos, muescas, incisiones, comas (Calvino, 2009, pp. 25 y 26).
\end{abstract}

En continuidad con la idea de "desnaturalización" propuesta en la figura de las ciudades análogas de Rossi o en la visión de Perec, estas descripciones no son para Foucault reproducción, sino desciframiento (Gorelik, 1999). Por ello el uso de metáforas, ambigüedades y figuraciones en la obra de Calvino consolidan un relato sobre la ciudad como jeroglífico a descifrar. Otra herramienta narrativa del escritor italiano consiste en la ucronía, es decir, la suposición de un pasado que podría haber sido diverso, "intercalar en la memoria de los hechos, las hipótesis del deseo” (Portelli; en Gorelik, 1999). El peso dela subjetividad en la construcción de la memoria es clave. La selección de qué recordar y qué no nos habla de la capacidad de la mente por construir una amalgama, a veces caprichosa, de recuerdos o momentos de una afectividad única que nos marcan, tal como sucede en el film de Chris Marker La Jetée (1962) ${ }^{3}$.

Más allá de seis ríos y tres cadenas de montañas surge Zora, ciudad que quien la ha visto una vez no puede olvidarla más. Pero no porque deje, como otras

3 La Jetée es un corto francés de ciencia ficción realizado íntegramente a partir de fotogramas. Marker elabora un concepto de memoria a través de la imagen fija, donde la guerra es un "dispositivo significante" que determina la posibilidad (ono) del recuerdo. La imagen recordada es huella, cicatriz del tiempo dosveces vivido, donde realidad e irrealidad se confunden. 
ciudades memorables, una imagen fuera delo común en el recuerdo. Zora tiene la propiedad de permanecer en la memoria punto por punto, en la sucesión de sus calles, y de las casas a lo largo de las calles, y de las puertas y las ventanas de las casas, aunque no haya en ellas hermosuras o rarezas particulares (...) Esta ciudad que no se borra de la mente es como un armazón o una retícula en cuyas casillas cada uno puede disponer las cosas que quiere recordar: nombres de varones ilustres, virtudes, números, clasificaciones vegetales y minerales, fechas de batallas, constelaciones, partes del discurso. Entre cada noción y cada punto del itinerario podrá establecer un nexo de afinidad o de contraste que sirva de llamada instantánea a la memoria. De modo que los hombres más sabios del mundo son aquellos que conocen Zora de memoria. (Calvino, 2009, p. 31)

El relato de esta ciudad guía hacia dos sentidos. Por un lado la imposibilidad de pensar la memoria como única y homogénea, pues cada sujeto tiene la capacidad de seleccionar qué recordar y qué no. Por otro lado, el texto refuerza elvalor de la mirada: cómo vemos determinarála posibilidad dela recordación y el olvido. Quien camina por Zora (o cualquier otra ciudad) almacenará un cúmulo de imágenes que a través del tiempo serán puestas al servicio de la memoria. Tales fueron las tareas que Benjamin llevó acabo en su proyecto de los pasajes que, como forma arquitectónica-urbana de fines del siglo XVIII y mitades del XIX, le permitió comprender realidades más complejas a pesar de la aparente superficialidad que la flânerie connotaba. La representación de la mercancía en la vida comercial de los pasajes fueron objetos de análisis banales e imposibles de encontrar en los libros de "ciencias sociales". De acuerdo con Hiernaux:

Es a la literatura que debe pedir la explicación involuntaria del sentido de la mercancía y de su presentación. También en textos imprevistos, como las guías de forasteros o los relatos de viajeros, Benjamin encontró un material de una riqueza inigualable para su propósito (1999, pp. 285 y 286).

\section{MEMORIA Y TIEMPO EN LA FIGURA DE LA “CIUDAD ANÁLOGA"}

Marco entra en una ciudad: ve alguien que vive en una plaza una vida o un instante que podrían ser suyos; en el lugar de aquel hombre ahora hubiera podido estar él si se hubiese detenido en el tiempo mucho tiempo antes, o bien si mucho tiempo antes, en una encrucijada, en vez de tomar por un camino hubiese tomado por el opuesto. (...) En adelante, de aquel pasado suyo verdadero o hipotético, él queda excluido; no puede detenerse; debe continuar hasta otra ciudad donde lo espera otro pasado suyo, o algo que quizás había sido un posible futuro y ahora es el presente de algún otro. Los futuros no realizados son sólo ramas del pasado: ramas secas.

— ¿Viajas para revivir tu pasado? - , era en ese momento la pregunta del Kan, que podía también formularse así: ¿Viajas para encontrar tu futuro?

Y la respuesta de Marco:

-El otro lado es un espejo negativo. El viajero reconoce lo poco que es suyo al descubrir lo mucho que no ha tenido y no tendrá (Calvino, 2009, p. 42). 
Hemos revisitado el concepto de memoria a lo largo del trabajo para referirnos a aquellas imágenes que "vuelven a presentarse" necesariamente en la experiencia de habitar, recorrer, vivir la ciudad. Perec nos advierte sobre la necesidad de interrogar lo que parece tan natural que ya olvidamos su origen. Calvino construye ciudades múltiples y fragmentarias, imposibles de ubicar en un único plano temporal. En esta intersección memoria-tiempo, el concepto de lugares de la memoria, de Pierre Nora, constituye un marco interpretativo de la historia. Antes que referirse a monumentos o a sitios materiales, "el lugar de la memoria es una noción abstracta, puramente simbólica, destinada a desentrañar la dimensión rememoradora de los objetos, que pueden ser materiales, pero sobre todo inmateriales, como fórmulas, divisas, palabras clave" (Nora, 1998, p. 32). El historiador francés explica que se trata de una historia crítica de la memoria y los modos en que se ha cristalizado; exploración de un sistema simbólico y de la construcción de un modelo de representaciones.

El aspecto fragmentario que desarrollan tanto Perec como Calvino nos conduce a la deconstrucción de sistemas simbólicos y representaciones que en la vida cotidiana "naturalizamos". "Notar que la ciudad no ha sido siempre lo que era" es el imperativo de Perec en pos de una búsqueda por una historia fragmentaria, que huye de los conceptos totalizadores o grandes relatos de la historia nacional. Esta corriente, innovadora respecto a la historiografía francesa, aporta como método el lugar como fuente y la memoria observada en los lugares (Allier Montaño, 2008). Una influencia de la obra de Pierre Nora fue Maurice Halbwachs, para quien la memoria está anclada en lo social y lo espacial. La historia es una, en tanto las memorias colectivas son diversas.

Los textos literarios que hemos analizado presentan diferentes tiempos en las ciudades, caracterizándolos como heterogéneos y múltiples. Lejos de intentar "deshistorizar" los espacios, estos fragmentos nos permiten ver las fracturas de la experiencia histórica. En este punto es factible la comparación precisa con el concepto de temporalidad con el que Deleuze (1987) caracterizó al cine moderno (Welles, Antonioni), donde hay una ruptura con la continuidad espacial y temporal de las narrativas. El tiempo ya no es sólo transcurso en el cine, sino historia y memoria. 'La 'imagen-tiempo' directa nos permite acceder a esa dimensión proustiana según la cual las personas y las cosas ocupan en el tiempo un lugar inconmensurable con el que ocupan en el espacio" (1987, p. 61). Según Deleuze, el tiempo no es lineal porque:

Por un lado, no hay presente que no esté poblado por un pasado y un futuro, no hay un pasado que no se reduzca a un antiguo presente, no hay un futuro que no consista en un presente por venir. La simple sucesión afecta a los presentes que pasan, pero cada presente coexiste con un pasado y un futuro sin los cuales él mismo no pasaría. Al cine le toca captar este pasado y este futuro que coexisten con la imagen presente (1987, p. 60). 
El valor inconmensurable del tiempo del que habla Deleuze es el que desarrolla Calvino, donde en un mismo espacio Marco Polo ejerce la capacidad de ocupar uno, dos, tres tiempos simultáneos y utiliza la ucronía, supone que el pasado podría haber sido otro y lo pone en el mismo plano que el futuro, rompiendo de esta manera la clásica visión lineal del tiempo, donde el presente y el futuro son producto del pasado:

Los habitantes de Valdrada saben que todos sus actos son a la vez ese acto y su imagen especular, que posee la especial dignidad de las imágenes, y esta conciencia les impide abandonarse ni un solo instante al azar y al olvido. (...) El espejo acrecienta unas veces el valor de las cosas, otras lo niega. No todo lo que parece valer fuera del espejo resiste cuando se refleja. Las dos ciudades gemelas no son iguales, porque nada de lo que existe o sucede en Valdrada es simétrico: a cada rostro y gesto responden desde el espejo un rostro o gesto invertido punto por punto. Las dos Valdradas viven una para la otra, mirándose constantemente a los ojos, pero no se aman (Calvino, 2009 , pp.67 y 68 ).

Siahondamos en la figura del espejo, podemos vislumbrar allíuna simbología de la dualidad y del tiempo. Valdrada es una ciudad construida a orillas de un lago de modo tal que el viajero que llega ve dos ciudades: una se reproduce por encima del agua y otra debajo. Cada uno de sus puntos se refleja en su espejo, perolejos deser simétricas, Calvino destaca sus diferencias, sus opuestos, como si de dos temporalidades se tratara.

Para Aldo Rossi la forma de la ciudad equivale a muchas temporalidades, por ello la figura de la ciudad análoga revela cómo los acontecimientos están grabados en los objetos, condensando valores arquitectónicos y culturales. Es una construcción histórica, pues las huellas culturales son producto del tiempo social y cultural, a la vez que marcas de él, pero que por la necesidad de mostrar el tiempo múltiple y el territorio fragmentado de la historia cultural de la ciudad, se resuelve como un espacio neutro, en el sentido de que compone y yuxtapone no sólo lugares, sino también tiempos y jerarquías. De acuerdo a Gorelik (1999), la metáfora teórica de Rossi pone en escena las figuraciones naturalizadas de la ciudad para deconstruirlas y así visualizar sus diferentes cualidades temporales y espaciales. ¿Puede una ciudad tener diversas memorias colectivas? ¿Qué tipo de memoria define a las ciudades? Calvino dibuja la ciudad de Maurilia calcada en sí misma. Una ciudad con múltiples representaciones y memorias colectivas, que nacen y mueren sin haberse conocido:

Esinútil preguntarse si éstos son mejores o peores quelos antiguos, dado que no existe entre ellos ninguna relación, así como las viejas postales no representan a Maurilia como era, sino a otra ciudad que por casualidad se llamaba Maurilia como ésta (Calvino, 2009, pp. 43 y 44). 


\section{CONSIDERACIONES FINALES}

La revisión que hemos presentado da cuenta de una miscelánea de enfoques y teorías acerca del espacio de las ciudades. Mediantela figura dela ciudad análoga advertimos la necesidad de deconstruir sus figuraciones naturalizadas, así como las diferentes cualidades temporales y espaciales. Desde disciplinas dispares, autores contemporáneos como Segura y Gorelik revisitaron este concepto como caja de herramientas para analizar ciudades argentinas y desentrañar los modos de representación persistentes y omitidos en ellas, convirtiendo la figura de Rossi en un buen instrumento para entender la articulación entre formas materiales y formas culturales. Lo morfológico, político, geográfico e histórico se superpone en sedimentaciones de un proceso histórico-urbano, donde las prácticas sociales naturalizan y legitiman una geografía urbana desigual.

En tanto que los aportes literarios de Perec y Calvino nos conducen a repensar la noción de ciudades análogas desde otro terreno, el de la novela y la narración como vehículos del pensamiento sociológico. Mirar con extrañeza el tiempo y el espacio, la vida cotidiana, los fragmentos de ciudad como los pasajes de Benjamin, se vuelve método y registro, descripción densa para una investigación cualitativa que no pierda de vista la deconstrucción de lo simbólico en la ciudad.

Por último, el lugar no menos importante de la memoria y el tiempo, ejes de articulación en las narrativas de Perec y Calvino, ambas ancladas en la urbe, el espacio y el tiempo, y en la búsqueda una ciudad deseada, soñada, imaginada, idealizada. Si en Calvino la ciudad es utópica, producto del deseo y la memoria, en Perec la ciudad es aquello que ha sido, pero que ya no es. Su vasto universo de sentidos se enmarca en los opuestos, como ese espejo negativo donde Marco Polo reconoce lo que es suyo y lo que nunca lo será:

Recorrer el mundo, surcarlo en todos los sentidos, nunca será algo más que conocer unas cuantas áreas, unas cuantas fanegas: minúsculas incursiones en vestigios desencarnados, escalofríos de aventura, búsquedas coaguladas en una bruma almibarada de la que nuestra memoria sólo guardará algunos detalles. (...) El mundo, no ya como un recorrido que hay que volver a hacer sin parar, no como una carrera sin fin, un desafío que siempre hay que aceptar (...), sino como recuperación de un sentido, percepción de una escritura terrestre, de una geografía que habíamos olvidado que somos autores (Perec, 2001, p. 119 y 120).

Y “acordarse", por lo tanto, dice Perec, de no olvidar lo que la ciudad fue en el pasado. 


\section{REFERENCIAS}

Allier Montaño, E. (2008). Los Lieux de mémoire: una propuesta historiográfica para el análisis de la memoria. En Historia y Grafía, 31, pp. 165-192.

Becker, H. (2015). Para hablar de la sociedad: La Sociología no basta. Buenos Aires: Siglo Veintiuno Editores.

Calvino, I. (2009). Las ciudades invisibles. Madrid: Siruela.

García Canclini, N. (2007). ¿Qué son los imaginarios y cómo actúan en la ciudad? En Eure, 33, (99), pp. 89-99.

Deleuze, G. (1987). La imagen-tiempo. Estudios sobre cine 2. Barcelona: Paidós.

Foucault, M. (2000). Un diálogo sobre el poder y otras conversaciones. Madrid: Alianza Editorial.

Gorelik, A. (1998). La grilla y el parque: espacio público y cultura urbana en Buenos Aires, 1887-1936. Quilmes, Argentina: Universidad Nacional de Quilmes.

Gorelik, A. (1999). Historia dela ciudad ehistoria intelectual.En Prismas, 3, pp. 209-223.

Gorelik, A. (2013). Miradas sobre Buenos Aires. Historia culturaly crítica urbana. Buenos Aires: Siglo Veintiuno Editores.

Hiernaux-Nicolas, D. (1999). Walter Benjamin y los pasajes de París: el abordaje metodológico. En Economía, Sociedad y Territorio, 2, (6), pp. 277-293.

Liernur, F. (2009). De las nuevas tolderías a la ciudad sin hombres: la emergencia de la “villa miseria” en la opinión pública (1952-1962). En Registros, 6, pp. 7-24.

Nora, P. (1998). La aventura de Les lieux de mémoire. En Ayer, 32, pp. 17-34.

Pascual, C. (2013). La villa y los territorios discursivos de la exclusión. En Bifurcaciones, 15 , pp. $1-14$.

Pascual, C. (2014). El giro espacial en historia. Derivas conceptuales y racconto historiográfico en Argentina. Imaginar los espacios de segregación localizados. En Revista de Direito da Cidade, 6, (2), pp. 427-452.

Perec, G. (2001). Especies de Espacios. Barcelona: Montesinos.

Perec, G. (1992). Tentativa de agotar un paisaje parisino. Rosario: Beatriz Viterbo. 
Rodríguez, M.G. (2011). Palimpestos: mapas, territorios y representaciones mediáticas. En revista Reflexiones Marginales, No 16. En línea:http://v2.reflexionesmarginales. com/index.php/num10-dossier-blog/213-palimpsestos-mapasterritorios-yrepresentaciones-mediáticas

Roldán, D. y Pascual, C. (2012). Escribir las periferias: representaciones literarias de la segregación urbana en Las Colinas del Hambre de Rosa Wernicke. En VIII Congreso Internacional de Teoría y Crítica Literaria Orbis Tertius. En línea: http:// www.memoria.fahce.unlp.edu.ar/trab_eventos/ev.2580/ev.2580.pdf

Rossi, A. (1966). La arquitectura de la ciudad. Buenos Aires: Gustavo Gili.

Segura, R. (2009). La persistencia de la forma (y sus omisiones). Un estudio del espacio urbano de La Plata a través de sus ciudades análogas. En Cuadernos de Antropología Social, 30, pp. 173-197.

Segura, R. (2015). Vivir Afuera. Antropología de la experiencia urbana. San Martín, Argentina: UNSAM Edita.

Snitcofsky, V. (2015). Las villas de Buenos Aires durante el Siglo XX. Imágenes literarias en perspectiva histórica. En Revista Eletronica do Centro Interdisciplinar de Estudos sobre a Cidade, 7, (10), pp. 282-311.

Stille, A. (19 de marzo de 2001). El valor histórico de los recuerdos. En diario La Nación, versión digital. En línea: http://www.lanacion.com.ar/56548-el-valor-historicode-los-recuerdos

Zusman, P. (2013). La geografía histórica, la imaginación y los imaginarios geográficos. En Revista de Geografía Norte Grande, 54, pp. 51-66. 


\section{DENTIFICACIOON DE LAAUTORA}

Carolina Laztra es Licenciada en Comunicación Social por la Facultad de Humanidades y Ciencias Sociales de la Universidad Nacional de la Patagonia (UNP), Comodoro Rivadavia, Argentina. Actualmente cursa el Doctorado en Comunicación en la Facultad de Periodismo y Comunicación Social de la Universidad Nacional de La Plata (UNLP). Es becaria doctoral del Consejo Nacional de Investigaciones Científicas y técnicas (CONICET). Susáreas de investigación y desarrollo académicos son la comunicación, la sociología y la antropología urbana.

\section{REGISTRO BIBLIOGRÁFICO}

Laztra, Carolina (2017). Representaciones de la ciudad análoga. Una revisión metodológica para los estudios culturales urbanos. InMediaciones de la Comunicación, 12(1), 91-105. 